\title{
Perspective
}

\section{Is psychiatry only neurology? Or only abnormal psychology? Déjà vu after 100 years}

de Leon J. Is psychiatry only neurology? Or only abnormal psychology? Déjà vu after 100 years.

Forgetting history, which frequently repeats itself, is a mistake. In General Psychopathology, Jaspers criticised early 20th century psychiatrists, including those who thought psychiatry was only neurology (Wernicke) or only abnormal psychology (Freud), or who did not see the limitations of the medical model in psychiatry (Kraepelin). Jaspers proposed that some psychiatric disorders follow the medical model (Group I), while others are variations of normality (Group III), or comprise schizophrenia and severe mood disorders (Group II). In the early 21 st century, the players' names have changed but the game remains the same. The US NIMH is reprising both Wernicke's brain mythology and Kraepelin's marketing promises. The neo-Kraepelinian revolution started at Washington University, became pre-eminent through the DSM-III developed by Spitzer, but reached a dead end with the DSM-5. McHugh, who described four perspectives in psychiatry, is the leading contemporary representative of the Jaspersian diagnostic approach. Other neo-Jaspersians are: Berrios, Wiggins and Schwartz, Ghaemi, Stanghellini, Parnas and Sass. Can psychiatry learn from its mistakes? The current psychiatric language, organised at its three levels, symptoms, syndromes, and disorders, was developed in the 19th century but is obsolete for the 21 st century. Scientific advances in Jaspers' Group III disorders require collaborating with researchers in the social and psychological sciences. Jaspers' Group II disorders, redefined by the author as schizophrenia, catatonic syndromes, and severe mood disorders, are the core of psychiatry. Scientific advancement in them is not easy because we are not sure how to delineate between and within them correctly.

\author{
Jose de Leon \\ University of Kentucky Mental Health Research \\ Center at Eastern State Hospital, Lexington, \\ $\mathrm{KY}$, and Psychiatry and Neurosciences \\ Research Group (CTS-549), Institute of \\ Neurosciences, University of Granada, \\ Granada, Spain, and Biomedical Research \\ Centre in Mental Health Net (CIBERSAM), \\ Santiago Apóstol Hospital, University of the \\ Basque Country, Vitoria, Spain
}

Keywords: Diagnostic and Statistical Manual of Mental Disorders; history, 20th century; history, 21st century; mental disorders; psychiatry; United States

Dr. Jose de Leon, UK Mental Health Research Center at Eastern State Hospital, 1350 Bull Lea Road, Lexington, KY 40511, USA.

Tel: (859) 246-8440;

Fax: (859) 246-8446;

E-mail: jdeleon@uky.edu

Accepted for publication October 16, 2014

First published online November 13, 2014

\section{Summations}

- 'Those who cannot remember the past are condemned to repeat it' (George Santayana).

- Jaspers was an inexperienced psychopathologist but a great thinker; rereading Jaspers' critiques of Wernicke, Freud, and Kraepelin leaves the author with unremitting déjà vu feelings.

- In the early 21 st century, the players' names have changed but the game remains the same. The US NIMH is reprising both Wernicke's brain mythology and Kraepelin's marketing promises, and the US neo-Kraepelinians have reached a dead end with the DSM-5. 


\section{Perspectives}

- McHugh, who described four perspectives in psychiatry (1) disease, (2) behaviour, (3) dimensional, and (4) self and life story, is the leading contemporary representative of the neo-Jaspersian diagnostic approach. Others neo-Jaspersians are Berrios, who focused on hybridity of symptoms; Wiggins and Schwartz; Ghaemi; Stanghellini; Parnas and Sass.

- Psychiatric terminology was developed in the 19th century but is obsolete for 21 st century science, and organisationally, includes three levels, symptoms, syndromes, and disorders. Learning from Bech's understanding of psychometrics and clinimetrics will help psychiatric researchers who are trying to develop contemporary terminology for describing psychiatric symptoms.

- Advancing knowledge at the core of psychiatry (catatonia, schizophrenia syndromes, and severe mood disorders) is not easy, as these severe mental illnesses lack diagnostic validation methods and clear distinctions between them.

'Those who cannot remember the past are condemned to repeat it' (George Santayana).

\section{One hundred years ago}

In 1913, a 30-year-old psychiatric trainee named Karl Jaspers, who was studying at the University of Heidelberg, had the arrogance to criticise the scientific status of psychiatry at that time by writing a long and complex book that he called 'General Psychopathology’ (1). This first edition of his book was substantially modified later as the fourth edition, which was finished in 1942 but rejected for publication by Nazi Germany. It was finally published in 1946; minimal changes led to the seventh edition, which was finally translated into English in 1963 (2).

Imagine that you are an attending psychiatrist trying to teach your residents about the scientific approach in psychiatry and one of them, a 30-year-old who is not a 'real resident' but one doing a voluntary rotation tells you, as Jaspers did, 'There seems to be no such thing as a common scientific psychiatry uniting all those engaged in psychiatric research. ... Psychiatrists must learn to think' (3). How would you respond? Not surprisingly, one of his attendings 'remarked with a friendly smile' that 'Jaspers ought to be spanked' (3). Until the end of his life, Jaspers insisted that psychiatrists must learn to think (4).

\section{The qualifications of the arrogant critic of psychiatry in the early 20th century}

As dispassionate scientists, let's try 'objectively' to enumerate Jaspers' qualifications for making such an arrogant critique in 1913. Let's start with Jaspers' quantitative qualifications and then move to his qualitative qualifications. When the first edition of his textbook was published, he had worked only 5 years in psychiatry, from 1908 to 1913. Moreover, in his philosophical autobiography he acknowledged that he last worked in a psychiatric hospital in 1915. In the fall of 1913, he took up psychology and started teaching it in the summer of 1914 (3). At that time psychology was included in the School of Philosophy. Now his teaching would probably be considered philosophy rather than psychology. After 1915, he never again acted as a psychiatrist. So in 1913 he could claim, at most, 5 years of psychiatric experience and throughout his long life (he lived to age 86) he could claim a maximum of only 7 years of psychiatric practice.

If one wants to assess the quality of Jaspers' psychiatric practice, his qualifications are further degraded by his inability to handle the physical activities required for being a physician. After many years of illness, he was diagnosed with bronchiectasis and secondary cardiac insufficiency in 1902 when he was 18 years of age. His prognosis was that he would not survive much beyond his $30 \mathrm{~s}$. As a matter of fact, Jaspers always considered himself a sick man $(5,6)$. The upper panel of Table 1 describes how he only worked in psychiatry as 'as a voluntary assistant' in research. Although he acted as a psychiatrist, his psychiatric activities were rather limited, as his precisely written description indicates. This description does not match that of a psychiatrist who diagnoses and treats his or her psychiatric patients. But he probably considered himself a psychopathologist rather than a psychiatrist. In the opening passage of the first edition of General Psychopathology (7), Jaspers introduced a distinction between the psychiatrist and the psychopathologist (Table 1, middle panel). So the arrogant critic could claim 5 years of interest in the scientific approach to psychiatry (his definition of a psychopathologist) before the first edition of his textbook, or 7 years over his lifetime.

Is 5 or 7 years sufficient to grasp psychiatry well enough to produce a coherent critique of it? Again, if you are dealing with an arrogant critic of your psychiatric approach and he has only 5 years of voluntary rotations because he is physically sick and cannot take care of patients, you would probably say no, unless he is 'a genius'. Was Jaspers a genius? 


\begin{abstract}
Jaspers only worked as a voluntary assistant in psychiatry
'My position in this group was peculiar (abnormal). I was only a voluntary assistant. My illness made it impossible for me to become a regular staff assistant. I did not live in the hospital, did not take my meals with the other physicians...' (3)

II was allowed to select my own cases for more detailed study. Wilmanns placed a special room at my disposal, in which I constructed intelligence and other tests, which at that time were just coming into use. ... Occasionally I was asked to make a report in court and to render expert affidavits in regard to accident insurance. Once, during Homburger's illness, I substituted for him at the preclinic. I became examining physician for nervous and mental diseases of the students' health insurance. Without being engaged in the regular daily routine duties of an assistant, the whole experience of a psychiatrist was in this way made accessible to me. The disadvantage of my position became an advantage. I could see and investigate everything without having my time occupied by routine duties. Besides carrying on my own investigations - I did not have a single patient from whose case I did not learn and remember something. I watched what my colleagues were doing, reflected on their procedures and my own, raised them to a higher level of conscious awareness, criticized them and pushed on to methodically pure procedures and formulations' (3)
\end{abstract}

\title{
Jaspers distinguished between psychiatrists and psychopathologists
}

'In the practical psychiatric occupations the interest is always in man in his individuality and wholeness; whether he is referred to a psychiatrist [for] observation, treatment, or therapy, or whether [the psychiatrist] gives an opinion of his [the person's] personality to the court, to other authorities, to the science of history, or whether the patient approaches him for consultation during visiting hours. While his work here deals completely with the individual case the psychiatrist searches... being a psychopathologist for general concepts and rules. In contrast with the psychiatrist, who in the practical profession is a living personality for whom science is only an instrument, for the psychopathologist science is its own goal. He wants to identify and recognize, characterize and analyze, but not only the individual person, but the general' (7)

Jaspers did not consider himself as a genius

'How was it possible that a sick man, who could hardly work properly for months at a time, sometimes almost for a whole year, ... How was it possible that a man of basically average ability finally got to the point - through persistency, through utilizing each hour - to become more clever in life, if I can express it in this way, and who, in the succession of his writings by no means unfolds a brilliant youthful genius but, inversely, progressed step by step, so that I perhaps did not write, until I was old, the best there was, and now think: If I had another half century before me ...' (8)

He did not consider himself one (Table 1, lower panel). In the interest of objectivity one has to acknowledge that, if Jaspers was not a genius, certainly he had a powerful mind. He trained as a physician but was able to become a teacher in psychology in 1915 (at 32 years of age) and then in philosophy in 1920 (at 37 years of age), despite having no formal training in these disciplines and not being welcomed by many of the philosophers at the University of Heidelberg (3). At the end of his life, he left a long list of philosophy books and a substantial international reputation (7).

Jaspers' accomplishments are particularly remarkable if one takes into account that for 8 years, during his most productive period, he lived a very difficult life, to the point that he planned to commit suicide with his wife rather than being taken to a concentration camp. This era started at age 53 (in 1937) when he was forced out of the university because he did not want to divorce his Jewish wife. It ended at age 61 (in 1945) when he was reinstated at the University of Heidelberg by the American army and asked to rebuild the Department of Philosophy. During these 8 challenging years, he lived as a recluse in his house with the company of his wife, his books, and his very well-justified fears $(3,5)$. A Spanish psychiatrist rotating at Heidelberg for several months testified that he tried to visit Jaspers at his house in 1942 but, despite his interest in seeing Jaspers and expressing admiration for his ideas, Jaspers did not open the door because he did not know him and just briefly talked to him through a peephole in the door of his apartment (9). During the Nazi period, Jaspers behaved no doubt as a good and honest human being, which is in contrast with the heavy involvement of other psychiatrists in the sterilisation and euthanasia programmes of psychiatric patients (10), or with his friend, Martin Heidegger, who also became an internationally known philosopher, but aligned himself with Nazi politics at the university and essentially betrayed his teacher and some of his closest friends due to their Jewish ancestry (11).

\section{Jaspers' critiques in the early 20th century}

When Jaspers entered psychiatry, academic psychiatry was dominated by a natural science approach, which was true in the Heidelberg department where Kraepelin was chairman from 1891 to 1903 (12), although the concept of psychiatry was flexible enough to accommodate Freud's hermeneutics (13).

To be precise about Jaspers' main contribution to psychiatric science, he proposed that psychiatry is a hybrid discipline requiring two methods, Explaining from the natural sciences and Understanding from the social sciences, which respectively provide an explanation of illness that follows the medical model and an understanding of psychiatric abnormalities that are variations of human living $(14,15)$.

Jaspers decided on this hybrid approach to psychiatry after criticising the approaches of two of Meynert's disciples (2). Meynert was a famous neuroanatomist and neuropathologist who was chairman of psychiatry in Vienna at the end of the 19th century. One of his disciples was Wernicke, who became famous at a young age after describing 
Critiques on Wernicke's ideas

'Aphasia became for Wernicke his guiding star. Along with the fact that these disturbances could be linked with certain parts of the brain he took over the concepts that were fruitful for such an analysis (though even here they were questionable) and applied them to all psychiatric disturbances while he entirely ignored the fact that aphasia is a disturbance of the psyche's tools not the psyche itself... so Wernicke explained all mental illnesses as illnesses of the "organ of association"' (2)

\section{Critiques on Freud's ideas}

'According to him everything psychic is 'determined', i.e. it is meaningful in our sense' (2)

'Freud is actually concerned with the psychology of meaningful connections and not with causal explanations as he himself believed' (2)

'The falseness of the Freudian claims lies in the mistaking of meaningful connections for causal connections. The claim is that everything in the psychic life, every psychic event, is meaningful (comprehensibly determined)' (2)

\section{Critiques on Kraepelin's ideas}

'General Paralysis was regarded for a time as the very 'paradigm' of mental illness. It was the only known entity' (2)

'Kahlbaum and later Kraepelin embarked on a new approach which hoped to arrive at disease-entities in spite of everything' (2)

'He persisted in shaping and reshaping these ideas while trying to bring to realization his notions of the disease-entity within special psychiatry as an actuality. Clinical pictures of diseases that have similar causes, a similar basic psychological form, similar development and course, similar outcome and a similar pathology and which therefore all present the same over-all picture, are genuine, natural-disease entities' (2)

'Let us now get an orientation on the results of this line of approach, which has been actively applied since about 1892 ... No real entity has been discovered by this method of approach. We have no scientific knowledge of any disease which satisfies the claims made for a disease-entity... The two disease-grouping of manic-depressive psychosis and dementia praecox are almost completely unknown so far as their causes and cerebral pathology are concerned. Their definition depends rather on the basic psychological form or on the course run (towards recovery or not) with varying emphasis placed on the one or the other' (2)

the sensory type of aphasia $(16,17)$. Wernicke thought psychiatry in simplified terms was 'only neurology'. The other Meynert disciple was Freud, who was initially also interested in aphasia and wrote his first book in 1891, On the Aphasias: a Critical Study (18), but went on to develop psychoanalysis and concluded that psychiatry was 'only abnormal psychology'.

Jaspers was very critical of Wernicke (Table 2 upper panel) to the point that, in the first edition of his book, he called him a 'brain mythologist' (19) because Wernicke's only method was Explaining. Jaspers was even more critical of Freud who went to the other extreme: Understanding is the only method needed in psychiatry (Table 2 middle panel).

Jaspers was also critical of the medical model of psychiatric illness defended by Kraepelin (Table 2 lower panel). It would be unfair to Kraepelin not to acknowledge some further developments in his career after Jaspers' critique in 1913. In 1917, Kraepelin opened the German Institute for Psychiatric Research, using the neurosciences of the time to try to improve psychiatric nosology (20). In 1920, in his last article $(21,22)$, Kraepelin acknowledged that his nosological system had failed, and his research programme had failed to provide the neuropathology for dementia praecox and manic-depressive insanity.

\section{Jaspers' solution in the early 20th century}

Jaspers proposed that psychiatric disorders are complex. Some psychiatric disorders follow the traditional medical model; Jaspers called them 'Group I, known somatic illnesses with psychic disturbances', with the best example being the general paralysis of the insane. Other psychiatric disorders are not medical disorders but variations of normality ('Group III', which Jaspers called disorders of personality). Situated between them are the psychoses (Group II) that, according to Jaspers, can be distinguished from normality but not clearly separated from each other (2).

\section{Déjà vu}

Rereading Jaspers' critiques of Wernicke, Freud, and Kraepelin leaves the author with unremitting déjà vu feelings. During the early part of the 21 st century he had the same problems with some of his contemporaries that Jaspers had 100 years earlier. Although nobody has extensively elaborated on this concept, this is not a completely original idea. Shorter, in his excellent textbook (23), A History of Psychiatry, describes the beginning of the 20th century as The End of the First Biological Psychiatry and the current era as The Second Biological Psychiatry. Maj (24), in a recent editorial on General Psychopathology, commented, 'The most striking analogy is that nowadays, exactly like 1 century ago, the enthusiasm brought about by a period of exceptional progress of research in neurosciences is being followed by some disillusionment, due to the limited relevance of that progress to the elucidation of the pathophysiology of mental disorders. To this disillusionment, the psychiatric field is now reacting in a way that resonates in several respects with Jaspers' analysis, making a revisitation of his General Psychopathology extremely useful.' Unfortunately the author's déjà $\mathrm{vu}$ sentiment generalised beyond the subject of 
Table 3. Déjà vu: early 20th (based on General Psychopathology) and early 21st century psychiatry

\begin{tabular}{lc}
\hline Early 20th century & Early 21st century \\
\hline EXTREME POSITIONS \\
\hline Psychiatry is only neurology: psychiatry only needs Explaining \\
\hline Nernicke & NIMH RDoC \\
\hline Psychiatry is only abnormal psychology: psychiatry only needs Understanding \\
\hline Freud & ? \\
\hline & PSYCHIATRY IS A HYBRID SCIENCE \\
(needs & Explaining and Understanding) \\
Neo-Jaspersians & Heterogeneity of disorders: McHugh \\
Hybridity of symptoms: Berrios \\
Multiperspectivalism approach: Wiggins \& Schwartz \\
or pluralistic approach: Ghaemi \\
Psychiatric interview: Stanghellini \\
Parnas \& Sass
\end{tabular}

biological psychiatry (23) and disillusionment with it (24). As Table 3 indicates, the names of the players have changed but the game is mostly the same as in the early 20th century.

\section{The 21st century equivalent of Wernicke}

The US National Institute of Mental Health (NIMH) has published the Research Domain Criteria (RDoC). According to Insel et al., 'the $\mathrm{RDoC}$ framework conceptualizes mental illness as brain disorders. In contrast to neurological disorders with identifiable lesions, mental disorders can be addressed as disorders of brain circuits' (25). The RDoC ignore mental disorders that do not fit the concept of a brain disorder. It is not clear whether the RDoC's developers think such mental disorders do not exist and all mental disorders are brain disorders, or whether some mental disorders which cannot be classified as mental disorders should be of concern for psychiatrists but not for psychiatric researchers (26). We could use Hyman (27), the prior NIMH director, who is 'in sync' with the RDoC, to clarify this point, 'Mental disorders are a diverse group of brain disorders that primarily affect emotion, higher cognition and executive function. The boundary between mental and neurological disorders is arbitrary' (27). One can conclude that, if Hyman represents what the NIMH really thinks, according to the NIMH, all mental disorders are brain disorders and that the NIMH researchers are the 'brain mythologists' of the 21st century. One suspects that there was some outrage from many early 20th century psychiatrists towards Jaspers' use of the term 'brain mythologist' and that this led Jaspers to eliminate the words 'brain mythologist' from later editions. In the translated English edition, it appears to be relegated to one place in the Introduction, 'These anatomical constructions, however, became quite fantastic, (e.g. Meynert, Wernicke) and have rightly been called 'Brain Mythologies'. (2). Anyway, these words are a good label for the RDoC approach. Moreover, when in 2006 Insel and Scolnick (28) proposed to cure mental illness, they were imitating Krapelin's marketing of a hundred years ago (20). Kraepelin marketed his Institute for Psychiatric Research by describing its goal: 'to make clear the nature and the sources of mental disturbances, and then to discover ways of preventing them, healing them or making them easier to bear' (20). Similarly, Insel and Scolnick (28) marketed the NIMH by writing, 'We now have the research tools necessary. Now is the time for research to set an ambitious goal of finding cures and preventive interventions for these disabling illnesses'. Thus, in the 21st century the US NIMH shares similarities both with Wernicke's brain mythology and Kraepelin's marketing promises. So with the passage of time, psychiatric researchers are becoming bolder as they become more ignorant of history.

\section{The 21st century equivalent of Freud}

Freud has no counterpart in the 21st century. He was a giant in marketing (14). His idea of the Unconscious, using a pseudoscientific approach, dominated the literature for a century and only now, is the scientific research on the Unconscious recuperating by means of what psychologists call dual-processing (29), which has not yet reached psychiatry. Although there is no equivalent of Freud in the 21st century, some psychiatrists, such as Aaron Beck and Isaac Marks, have further developed psychological concepts and applied them to the development of specific psychotherapy techniques for specific disorders. These techniques tend to be used more by psychologists and other psychotherapists than by psychiatrists. Moreover, all experts trying to assess the effectiveness of psychotherapy are dealing with unresolved issues pointed out 100 years ago by Jaspers. These include the conceptual difficulty of (1) using psychotherapy as a treatment for bio-medical disorders when it is really as an encounter between human beings, (2) distinguishing the effectiveness of the therapy versus the therapist's effectiveness, and (3) explaining which processes are responsible for the effectiveness of psychotherapy $(30,31)$. The first attempts to consider the methodological issues involved in integrating psychotherapy and the neurosciences, particularly brain imaging, are occurring $(32,33)$. 
In conclusion, despite the cyclic nature of history implied in this article, Freud was such a significant and disturbing figure in the early 20th century that no 21 st century reincarnation of Freud is possible.

\section{1st century Kraepelinians or neo-Kraepelinians}

In 1970 Guze and Robins (34) presented a programme at Washington University in St Louis to establish the diagnostic validity of a psychiatric illness in five phases: (1) clinical description, (2) laboratory studies, (3) delimitation from other disorders, (4) follow-up studies, and (5) family studies. US psychiatrists are not historically inclined, so it is not surprising that Guze and Robins (34) did not quote Kraepelin's textbook but rather, Bleuler's schizophrenia textbook. When the US psychiatrist Klerman (35) baptised the Washington University approach as neo-Kraepelinian, he explained that they had been influenced by Kraepelin through the reading of the Mayer-Gross textbook, which transferred the Heidelberg school's teachings to the United Kingdom (26). The neo-Kraepelinian revolution was advanced by Spitzer, who forgot about validity and focused on reliability after settling for 'diagnostic democracy', which led to the multiplication of psychiatric disorders in the DSM-III $(36,37)$ and the failure to define normal mental health. This historical process finally led to the current dead end of the DSM-5 (38).

\section{1st century Jaspersians or neo-Jaspersians}

The leading follower of the Jaspersian diagnostic approach in the 21st century is McHugh (Table 3), who further elaborated on Jaspers' heterogeneity by describing four perspectives in psychiatry: (1) disease, (2) behaviour, (3) dimensional, and (4) self and life story (39). In 2005, in a critique of early DSM-5 plans, McHugh explained that, as with medical classifications, DSM-5 should also be arranged around etiopathic clusters (40).

Jaspers' General Psychopathology has so many ideas that need to be further developed that it is not surprising the author has found at least three more groups of neo-Jaspersians in the early 21 st century (Table 3). The hybridity of all psychiatric objects and a sophisticated elaboration on a model of how psychiatric symptoms can develop have been the themes of Berrios's latest articles $(41,42)$. Jaspers' concept that the research method should fit the type of disorder has been reworked as a 'multiperspectivalism' approach by Wiggins and Schwartz (43), and as a 'pluralistic' approach by Ghaemi (44). Other neoJasperians, such as Stanghellini (45) or Parnas and Sass $(46,47)$ have written on practical issues, including the psychiatric interview.

\section{The qualifications of the arrogant critic of psychiatry in the early 21 st century}

The author has tried to be a dispassionate scientist and has criticised his hero, Jaspers. He has presented him as an arrogant psychiatric trainee and a 7-year psychopathologist, but also as a persistent and hard-working man who, in spite of his lack of philosophical training, became a renowned international philosopher after surviving with honor one of the darkest times in human history, the Nazi period.

To be fair, Jaspers should have the opportunity to dispassionately criticise the qualifications of this author as a critic of 21 st century psychiatry. As Jaspers is dead, the author has to use what Jaspers called Understanding and provide critiques from Jaspers' point of view. Jaspers would be relieved to know that the author has been given an essentially healthy life which allowed him to start his residency in psychiatry in 1982 (age 23) leading to 32 years of experience (current age 55) in clinical psychiatry, combined with research activities. As books are no longer fashionable in the 21st century, Jaspers would have to use PubMed peer-reviewed articles to assess his scientific production. As of 9 May 2014, Jaspers would have found more than 250 articles in PubMed by the author, the first one in 1985. Jaspers may have observed that until 1996, when the author took his current job, he had 52 articles, of which Jaspers could consider half to be focused on psychopathology, since they discuss psychiatric symptoms. The second most common theme in these 50 articles is pharmacology, which was very underdeveloped in the early 20th century. Jaspers would have been pleased that after 100 years psychiatrists have finally found something to alleviate the suffering of psychiatric patients. However, if he had read a recent editorial by the author, he would have learned that psychiatrists cannot take much credit for the discoveries of psychiatric drugs, since they were mainly a series of serendipitous findings (48). With the help of current medical students who are computer wizards, Jaspers might have found a recent autobiographical note by the author for his university's medical student journal (49). Although Jaspers had a major disagreement with his school principal when he was around 10 years of age, he became a law-abiding citizen but he always challenged authoritarian rules which he could not understand and refused to follow the Nazi request to divorce his Jewish wife (5). Jaspers probably would have concluded that the author became a coward in 1996 when he moved to his current job and decided to stop doing psychopathological research on psychiatric symptoms, which was no longer fashionable in the United States. Moreover, Jaspers might have thought that the author was trying to justify himself in his autobiographical statement (Table 4) and would 
Table 4. Biographical quotes by author

Author's justification for abandoning psychopathological research for psychopharmacological research

'When I moved to Kentucky 18 years ago, I decided to become better at explaining treatments by becoming a psychopharmacologist. Then I became a pharmacist (please keep my first secret: physicians do not know pharmacology). My brain is very good for mathematics (it comes from my father, an engineer and professor of mathematics) so I started developing mathematical pharmacological models to treat my patients' (49)

probably have further commented that the author has tried to run from his prior interest in psychopathology by writing 200 articles in his current job, most of them in pharmacology. The young Jaspers might have labeled him with some disdain 'a shameful coward' hiding from the interest in psychopathology he displayed as a young psychiatrist in order to accommodate the establishment in US psychiatry.

Jaspers wrote extensively on the concept of limit situations. According to Jaspers, 'limit situations are characterised by inevitable antinomies which prevent a person going as usual' (50). Jaspers was an 'aristocratic' man (4) and a shy intellectual academician who had dealt with significant medical problems since childhood; therefore, he would have understood, in this short biographical comment, the author's withholding of the information that in 2009, he was diagnosed with colon cancer, requiring surgery and chemotherapy. On the other hand, Jaspers would have pointed out that it was necessary to discuss this as a 'limit situation' and that it was only fair to discuss the author's illness as the author, likewise, discussed Jaspers' illness. Moreover, Jaspers would have wondered if the cancer, as a 'limit situation', led the author to question his choice to abandon psychopathology research. Moreover, after reading another article by the author (14), he would have pointed out that the author's daughter's entrance into medical school in August 2013 with plans to study psychiatry was a second limit situation pushing the author to write about the scientific approach in psychiatry $(14,26,36,48,51,52)$ and go back to his interest in Jaspers' writings which he read during his residency before the triumph of the DSM-III in Europe $(51,52)$.

Jaspers might conclude that the author's 32 years of experience in clinical practice appear to be a good first step for offering opinions about 21st century psychiatry. The 250 articles appear to indicate a hardworking man. He would have been kind with the last 200 articles in which the author intruded into the areas of pharmacology, genetics, and statistics, in which he had no training. The lack of philosophical training and reading by the author would probably have been problematic for Jaspers, who thought that his contemporary psychiatrists 'must learn to think' (3). There is no doubt that early 20th century psychiatrists were much better educated in philosophy and more experienced in philosophical thinking than the author. On the other hand, the author thinks life is profoundly paradoxical. He would like to conclude by describing the paradoxical opinion of Kurt Schneider. There is no doubt that Schneider was a highly reputed and experienced clinician (53-55). He was a great admirer of Jaspers and helped him with the third and following editions of General Psychopathology after Jaspers left his clinical practice (55). Schneider's textbook (56) helped to simplify and disseminate Jaspers' ideas among clinical psychiatrists (53-55). Schneider always recommended the first edition of General Psychopathology to his students and thought that the fourth and later editions had too much philosophy $(6,55)$. Thus, Schneider valued the book written by the 30-year-old Jaspers, a young iconoclast with only 5 years of experience in psychopathological research and limited philosophical training, mainly influenced by Max Weber (57). Schneider preferred him to the 59-year-old Jaspers, who was a well-read philosopher heavily influenced by Kant (7). Jaspers finished the fourth edition of General Psychopathology after not engaging in clinical activities for almost 30 years. Early 21 st century psychiatry residents appear to agree with Schneider that the English translation of General Psychopathology is too philosophical (14) and 'too much' for their brains. (Or is it too much for their minds?)

\section{Learning from the past}

The ambitious goal of this article is to prevent early 22nd century psychiatrists from writing an article comparing their time with ours. What can be learned from these 20th and 21st century psychiatrists and their mistakes?

To answer that question, one must follow Jaspers' recommendation and 'learn to think' even if it requires taking oneself 'out of the box' and acknowledging, as McHugh did, that psychiatry is 150 years behind medicine (38). Moreover, Berrios explained that psychiatry is stuck with 19th century language based on the scientific knowledge of that time (40). Let's think critically about psychiatric terminology. To simplify, one can say that it is organised according to three levels: symptoms, syndromes, and disorders. It is really one basic level, symptoms, which can be organised into two superior and competing levels: syndromes and disorders. In the beginning symptoms are arranged according to syndromes, but as knowledge increases, disorders can be defined within the syndromes. 
Table 5. Recommendations for current clinicians and the training of future psychiatrists

DIAGNOSIS

Symptom level

There is no easy answer. The author would prefer to have a good global system to assess all kinds of psychiatric symptoms, but the only one of which he knows has been forgotten. It is the European system called AMDP*(59) (reviewed in 52). To train residents, he recommends the AMDP supplemented with more specific scales for catatonic, schizophrenic or affective symptoms

Syndromic/disorder level

As the author thinks that the DSM- 5 is a dead end, he proposes the use of a much simpler way of diagnosing patients based on McHugh's teachings $(39,40)$. McHugh has absorbed the most important of Jaspers' teachings and further elaborated upon them during a clinical career of nearly 50 years

-Jaspers' Group I (organic mental diseases): Get yourself trained as best as possible in neurology, particularly in areas overlapping with psychiatry (cognitive and dementing

illness, movement disorders and epilepsy) and study neurological textbooks and journals when presented with problematic cases

-Jaspers' Group III (variants of normality): Pay attention to McHugh's perspectives on behaviour, dimensional, and self and life story

-Jaspers' Group II: The author likes to redefine them as catatonia syndrome, schizophrenia syndrome and severe mood disorders. Psychiatrists need to be very sophisticated in

the diagnosis of disorders from Groups I and III, unless they want Group II contaminated by the other two Groups

The author's recommended scales for catatonia: KANNER scale (60)

schizophrenia: Andreasen ${ }^{\dagger}(61-63)$

depression: Hamilton (64)

mania: Young (65)

TREATMENT

-Reality: Today's 'confused' clinicians do not appear to treat psychiatric disorders, but rather psychiatric syndromes, according to medication profiles and symptoms measured in a dimensional way (66)

-Basic principles for education:

(1) Study pharmacology and learn pharmacokinetic and pharmacodynamic mechanisms of each psychiatric drug so as to better personalise treatment for each patient (67)

(2) Evidence-based medicine (EBM) approach: (a) Efficacy: Be familiar with psychiatric organisation treatment guidelines for 'disorders'. When the indication is off-label, be more restrained in the use of medication and do more comprehensive documentation. (b) Safety: Be familiar with adverse drug reactions (ADRs) described in the prescribing information and with the ADR scales relevant for your practice. Scales suggested: for ADR presence ${ }^{\ddagger}$ (68) and for movement disorders: AIMS ${ }^{\S}$ (69) and NRS ${ }^{\Uparrow l}$ (70)

(3) The pharmacological guidelines for each drug should combine EBM and knowledge of pharmacokinetic and pharmacodynamic mechanisms in a practical way (71), for better use of each psychiatric drug in each patient

-Jaspers Group I (organic mental diseases): Be as good as a neurologist if you are treating these patients

-Jaspers Group III (variants of normality): (a) Psychopharmacology has a very limited role in treating these variants of normality and 'minor' psychiatric disorders. (b) Collaboration with people delivering the educational methods we call psychotherapy is fundamental. And (c) Psychiatrists need to humbly acknowledge that collaboration with religious and legal institutions is important, since they have different perspectives but for centuries have also been involved in helping people with these types of problems. Most psychiatrists would acknowledge that Alcoholic Anonymous is a very important part of treatment, and yet no objective observer could deny that it is firmly based in religious principles

-For Jaspers Group II: (a) Medications and other biological therapies such as electroconvulsive therapy have a crucial role. And (b) psychoeducational approaches for patient and family are fundamental for helping to manage these complex, usually chronic and long-lasting, disorders

\footnotetext{
"Association for Methodology and Documentation in Psychiatry (AMDP), originally called Arbeitsgemenschaft fur Methodic und Dokumentation in der Psychiatrie.

${ }^{\dagger}$ The Andreasen scales are called Scale for the Assessment of Negative Symptoms (SANS) (60) and Scale for the Assessment of Positive Symptoms (SAPS) (61). Using factor analyses, Andreasen and others describe schizophrenia symptoms as more properly classified in three dimensions: positive, disorganised, and negative. No official modification of these scales has been made, which would permit classification in three dimensions but some studies have used them (62).

${ }^{\ddagger}$ The Liverpool ADR scale helps establish causality, the relationship between medication and an ADR.

${ }^{\S}$ AIMS: Abnormal Involuntary Movement Scale (68).

"NRS: Neurological Rating Scale (69).
}

Another important conceptual/organisational issue in psychiatry will result from acknowledging that the DSM-III had an impossible task in serving both the needs of clinicians and researchers. That guaranteed a catastrophe, which has now occurred. The DSM-5 is not helpful for clinicians and the NIMH researchers think that it 'lacks validity' (58); the latter believe that the RDoC alternative is the way to go (25). The remainder of this article attempts to suggest a research agenda for the future of psychiatry. The recommendations for practicing clinicians are described in Table 5 (59-71).

The language of psychiatric symptoms appears to have been carved in stone in the 19th century. The humongous problem is that DSM-III tried to establish good inter-rater reliability at the disorder level without first dealing with the symptom level (14). As Berrios indicated, it is very important to create a new language for describing psychiatric symptoms using 21st century knowledge (42). Learning from Bech's understanding of psychometrics (72) and clinimetrics (73) will not hurt psychiatric researchers who are trying to develop contemporary psychiatric terminology to describe symptoms.

During his lifetime $(74,75)$, Kraepelin was criticised for thinking he was going from symptoms to disorders when he was going from symptoms to syndromes. Unfortunately, even today psychiatry cannot aspire to 
designate psychiatric disorders; only syndromes can be defined for Jaspers' Groups II and III disorders. Psychiatric syndromes are very important because they are used by clinicians to select treatments (Table 5).

Before commenting on the disorder level, the author has to make a painful statement of fact. Psychiatry overlaps with neurology; it is not the same as neurology, but it appears to lose disorders to neurology. Neurologists usually lack the flexibility and knowledge to use what Jaspers calls Understanding in their diagnostic schemes. However, once the neuropathology of a psychiatric disorder is well established, the natural historical process is that the disorder moves from psychiatry to neurology. In Jaspers' time epilepsy was a psychiatric disorder. As a matter of fact, epilepsy is listed by Jaspers in his Group II with schizophrenia and manic-depressive illnesses, although in the 21st century there is no doubt that epilepsy is a neurological disorder. Some of the most difficult epileptic patients have such a strong 'psychiatric' component in the diagnosis and treatment that most common sense neurologists ask psychiatrists with expertise in that area for help. This perspective comment cannot extensively review the situation of Alzheimer disease but it has been briefly reviewed elsewhere (76). In Jaspers' day, Alzheimer disease was a psychiatric disorder since psychiatric researchers such as Alzheimer were both psychiatrists and neuropathologists. Psychiatrists no longer have neuropathological expertise, so the research on dementing disorders is increasingly conducted by neurologists (76). Psychiatrists usually lack the skill and knowledge to diagnose dementing illnesses as capably as neurologists. Ask a psychiatrist what hippocampal sclerosing of ageing is (77).

For discussing the disorder level, the author is going to use Jaspers' classification system. For Group I, called organic mental disorders in the DSM-III, research in the neurosciences is fundamental. Unfortunately, the riddle of Alzheimer disease appears much more complex to solve than expected (76). We now know that brain mechanisms are extraordinarily complex and our models have been too simplistic. The author suspects that dementing illnesses may not be part of psychiatry in the early 22nd century; they will probably be part of neurology.

Scientific advances directed towards variants of normality (Jaspers' Group III disorders) are difficult because of the need to challenge preconceived ideas. An excellent example of using fruitful new ideas to redefine preconceptions is occurring in psychosomatic medicine through the efforts of Fava et al. (78). Collaboration with researchers in the social and psychological sciences is fundamental in better defining and investigating these disorders/abnormalities (79). A very significant linguistic problem is that most of the practical language in psychiatry in the area of Understanding or interpretations is contaminated by19th century Freudian ideology. The author thinks that concepts such as defense mechanism are very helpful for clinicians but they need to be reformulated, taking into account what we know about the brain's dual-processing mechanisms, and systematically investigated in the clinical environment as much as possible, rather than being derived from psychoanalytic theory; psychoanalysis is a pseudoscience (14). As a matter of fact, many of these ideas and terms were taken by Freud from prior thinkers (80) and need to be rescued from Freudian ideology. After seeing the limitations of traditional physics in dealing with microcosms and macrocosms in the 20th century, we need to acknowledge that our scientific methods were developed and perfected in the natural sciences by dealing with physical objects, but most subjective human phenomena cannot be approached the same way.

Jaspers' Group II is the core of psychiatry, usually called severe mental illness, which affects $\sim 5 \%$ of the population of developed countries (48). In the view of the author, severe mental illness includes the catatonia syndrome, the schizophrenia syndrome and the severe mood disorders (bipolar disorders and severe cases of depression). They are the core of the 'business' of psychiatry from the point of view of treatment (Table 5). Research in Group II disorders is very challenging; neuroscientists may help but they cannot crack the codes since we are not sure how to distinguish these disorders correctly among themselves, as Jaspers described. They are really syndromes. As a matter of fact, the author doubts that the diagnosis of schizophrenia will exist in the early 22nd century; moreover, it was probably an accident of history that Kraepelin joined together such a heterogeneous group of disorders and separated them from the manic-depressive illnesses. Testing nonKraepelinian models may be a good idea. The author likes the 20th century Leonhard's model of classifying psychoses (76), which has mainly been ignored by US psychiatry. However, building new 21st century models may be required.

In the last few years, there has been huge spending on psychiatric genetics with the promise that this may bring about miraculous advances; these studies have been supported to the detriment of clinically relevant research. In one of the few critical reviews of these expenses, Sadler (81) has estimated that these studies may have taken from $4 \%$ to $8 \%$ of the NIH expenditures for three psychiatric illnesses during the reviewed years of 2008 and 2009. It is likely that the most recent genome-wide association studies were even more costly, but demonstrated only what Jaspers proposed, that there is no clear delimitation between schizophrenia and severe 
mood disorders since they demonstrate substantial genetic overlap. Moreover, substantial overlap exists in genes associated with schizophrenia, severe mood disorders and even autism. Therefore, it is not clear how or when these genetic findings can contribute to the challenging process of developing new psychiatric medications (82). In 2013, a new brain imaging initiative was launched in the United States, which will take money from the National Institutes committed to psychiatric research (83). These Institutes budgets had already been cut in recent years and are only able to provide funding for a very small percentage of submitted grants, canceling the future development of new US psychiatric researchers. This investment in brain imaging occurs despite the clinically unreliable results provided by psychiatric imaging methods (84) and the improbability that they can speed the development of new psychiatric treatments (85).

\section{Conclusion}

This perspective proposes that forgetting history is a mistake since it frequently repeats itself in a somewhat modified way. In General Psychopathology, Jaspers criticised early 20th century psychiatrists including Wernicke, the 'brain mythologist' who thought psychiatry was only neurology. Jaspers criticised Freud, who confused meaningful connections with causal connections and thought that psychiatry was only abnormal psychology. Jaspers criticised Kraepelin, who did not see the limitations of the medical model in psychiatry. Jaspers proposed that psychiatric disorders are complex, and include a few that follow the medical model, others which are variations of normality and, situated between them, schizophrenia and severe mood disorders.

In the early 21 st century, the names of the players have changed but the game remains fundamentally the same as 100 years ago (Table 3 ). The US NIMH is exercising the privilege of reprising both Wernicke's brain mythology and Kraepelin's marketing promises, indicating that psychiatric researchers are becoming bolder as they become more ignorant of history. Research psychologists are more humble (29), but are still recuperating from the deleterious effects of Freud, the great marketer. The neo-Kraepelinian revolution started at Washington University, was catapulted to the forefront by Spitzer with the DSM-III, and appears to have reached a dead end with the DSM-5. The leading follower of the Jaspersian diagnostic approach in the 21st century is McHugh, who described four perspectives in psychiatry: (1) disease, (2) behaviour, (3) dimensional, and (4) self and life story. Another 21st century Jaspersian is Berrios, who expanded on the hybridity of all psychiatric objects and elaborated on a model describing how psychiatric symptoms can develop. Jaspers' concept that the research method should fit the type of disorder has been reworked as a 'multiperspectivalism' approach by Wiggins and Schwartz, and as a 'pluralistic' approach by Ghaemi. Other neo-Jaspersians, such as Stanghellini or Parnas and Sass, have written about practical issues including the psychiatric interview.

The paradox of this story is that the loyal Kurt Schneider preferred the ideas of the 30-year-old Jaspers, a young iconoclast with only 5 years of experience in psychopathological research and limited philosophical training, rather than the 59-year-old Jaspers, a well-read philosopher who wrote a too-philosophical General Psychopathology, which is the version that has been translated into English, to the dismay of psychiatric residents in the 21 st century who can barely understand it.

Can psychiatry learn from its mistakes? Perhaps not, since that requires humility and some bitter medicine. Psychiatric language, at its three levels, symptoms, syndromes, and disorders, is really one basic level, symptoms, which can be organised into two superior and competing levels: syndromes and disorders. In the beginning symptoms are arranged according to syndromes but, as knowledge increases, disorders can be defined within the syndromes. This psychiatric language was developed by 19th century thinkers, but we inhabit the 21st century. Nineteenthcentury terms are somewhat helpful for clinicians, but are not sufficient for 21st century science. The first step towards a more scientifically valid psychiatry is to acknowledge that we must agree on the first level of psychiatric terminology and develop appropriate inter-rater reliability at the level of psychiatric symptoms. Reading Berrios $(41,42)$ and Bech $(72,73)$ may be helpful.

Clinicians appear to be treating patients using a syndromic approach (66). It appears to be better to drop any attempt to develop DSM-6 and move to a simpler system for diagnosing patients. In the author's opinion, McHugh $(39,40)$ offers the best approach.

Scientific advances in what Jaspers called Group I disorders appear to transfer disorders to the field of neurology, since psychiatrists no longer have expertise in neuropathology. Scientific advances in what Jaspers called Group III disorders, variations of normality, require collaborating with researchers in the social and psychological sciences. There is a huge practical need to rescue the language of Understanding or interpretation from Freudian ideology. Jaspers' Group II disorders (the catatonia and schizophrenia syndromes and the severe mood disorders) are the core of psychiatry and affect $\sim 5 \%$ of the population of developed countries. The author thinks that scientific advancement regarding these is not easy because we 
are not sure how to delineate between them correctly, as Jaspers described. There are no gold standards such as neuropathology to validate them. NonKraepelinian models need to be tested. Among neoKraepelinian models, testing the Leonhard model of psychoses is relatively simple, once there is the willingness to do it (76). Developing new nonKraepelinian models that aspire to have validity appears to be a very complicated task, since genetic overlap of schizophrenia and severe mood disorders indicate, as Jaspers described, that there is no clear boundary between them. As far as the author can predict, a specific and valid narrowly defined psychiatric illness may include some patients who are currently included in schizophrenia and others who are included in the severe mood disorders. As both genetic and clinical findings indicate patient overlap, even using complex statistical techniques may not help to separate them since statistical techniques do not appear to help medical nosology. Oncology is progressing by using tissue findings to link mechanisms and genes, but this not an option in psychiatry. The author proposes three ideas that may help to clarify the field: (1) It is important to separate entities that may have different physiopathological mechanisms, in the sense that patients with catatonic syndromes may need to be studied separately from patients with schizophrenia, severe mood disorder or autism who have never presented catatonic syndromes; (2) non-familial forms of psychiatric disorders may not necessarily have the same genetic and/or environmental loading as familial forms and (3) careful studies of families with high loading of severe mental illnesses using sophisticated new thinking are needed. The last two ideas come from Alzheimer disease research. Alzheimer disease appears to be a group of illnesses sharing a common neuropathology and include a complex mix of some familial forms with very specific genes with heavy genetic loading and others that appear to reflect complex gene-environmental interactions. It is possible that studying familial forms may help to segregate a few patients from the continuum between schizophrenia and severe mood disorders, but these small new nosological categories may tell little about the remaining patients unless we hit the lottery and they help us discover something about specific brain mechanisms that can provide some clues about other brain mechanisms in other familial and non-familial forms of schizophrenia and severe mood disorders.

\section{Acknowledgements}

The author acknowledges Lorraine Maw, M.A., at the Mental Health Research Center at Eastern State
Hospital, Lexington, KY, who helped in editing this article. In his e-mails to the author, Prof. Dr. Heinz Häfner provided helpful clarifications to the author about the relationship between Karl Jaspers and Kurt Schneider.

\section{Financial Support}

This article received no specific grant from any funding agency, commercial business, or not-forprofit institution.

\section{Statement of interest}

Dr. de Leon personally develops his presentations for lecturing, has never lectured using any pharmaceutical or pharmacogenetic company presentation, and has never been a paid consultant for pharmacogenetic or pharmaceutical companies. In the past, Dr. de Leon has received researcher-initiated grants from Eli Lilly (one ended in 2003 and the other, as co-investigator, ended in 2007), from Roche Molecular Systems Inc. (ended in 2007) and, in a collaboration with Genomas Inc., from the NIH Small Business Innovation Research programme (ended in 2010). He was on the advisory boards of Bristol-Myers Squibb (2003/2004) and AstraZeneca (2003). Roche Molecular Systems supported one of his educational presentations, which was published in a peer-reviewed journal (2005). His lectures have been supported once by Sandoz (1997), twice by Lundbeck (1999 and 1999), twice by Pfizer (2001 and 2001), three times by Eli Lilly (2003, 2006, and 2006), twice by Janssen (2000 and 2006), once by Bristol-Myers Squibb (2006), and seven times by Roche Molecular Systems Inc. (once in 2005 and six times in 2006).

\section{References}

1. JASPERS K. Allgemeine Psychopathologie. Bin leitfaden fur studierende, arzte und Psychologen, 1st edn. Berlin: Springer, 1913.

2. JASPERS K. General Psychopathology Translated from the German 7th edition by Hoenig $\mathbf{J}$ and Hamilton $\mathrm{MH}$ ) Manchester, UK: Manchester University Press, 1963.

3. JASPERS K. Philosophical autobiography. In Schilpp PA editor The Philosophy of Karl Jaspers. La Salle, IL: Open Court Publishing Co, 1957: 5-94

4. LóPEZ IBOR JJ. 100th anniversary of the birth of Karl Jaspers. Actas Luso Esp Neurol Psiquiatr Cienc Afines 1982;10:321-330.

5. KIRKBRIGHT S. Karl Jaspers: A Biography. Navigations in Truth. New Haven, CT: Yale University Press, 2004.

6. HÄFner H. Karl Jaspers. 100 years of 'Allgemeine Psychopathologie' (General Psychopathology). Nervenarzt 2013;84 1281-1282, 1284-1286 1288-1290.

7. Miron R. Karl Jaspers from Selfhood to Being. Amsterdam/ New York: Rodopi, 2012. 
8. JASPERS K. A self-portrait. In: Ehrlich LH, Wisser R, editors. Karl Jaspers Today: Philosophy at the Threshold of the Future. Washington, DC: Center for Advanced Research in Phenomenology \& University Press of America, 1988: 1-25.

9. Solé Sagarra J. Historia vivida de la psiquiatría: 19401945. IMP-Psiquiatría 1990;2:11-14.

10. Strous RD. Hitler's psychiatrists: healers and researchers turned executioners and its relevance today. Harv Rev Psychiatry 2006;14:30-37.

11. Ettinger E. Hannah Arendt. Martin Heidegger. New Haven, CT: Yale University Press, 1995.

12. Fuchs T, Herpertz S. The centennial of Karl Jaspers'. Psychopathology 2013;46:279-280.

13. Berrios GE, Marková IS. Assessment and measurement in neuropsychiatry: a conceptual history. Semin Clin Neuropsychiatry 2002;7:3-10.

14. DE LEON J. Is psychiatry scientific? A letter to a 21 st century psychiatry resident. Psychiatry Investig 2013;10:205-217.

15. Berrios GE. Jaspers and the first edition of Allgemeine Psychopathologie. Br J Psychiatry 2013;202:433.

16. Graves RE. The legacy of the Wernicke-Lichtheim model. J Hist Neurosci 1997;6:3-20.

17. Lanczik M, KeIL G. Carl Wernicke's localization theory and its significance for the development of scientific psychiatry. Hist Psychiatry 1991;2:171-180.

18. Freud S. On the Aphasias: A Critical Study (Translated by Stengel E.) New York: International University Press, 1953.

19. FranZeK E. Influence of Carl Wernicke on Karl Leonhard's nosology. Psychopathology 1990;23:277-281.

20. Kraepelin E. The German institute of psychiatric research. J Nerv Ment Dis 1920;51:505-513.

21. KraePelin E. Die Erscheinungsformen des Irreseins. Z Gesamte Neurol Psychiatr 1920;62:1-29. (Translated in 1992).

22. Kraepelin E. The manifestations of insanity. Hist Psychiatry 1992;4:509-529.

23. Shorter E. A History of Psychiatry. From the Era of the Asylum to the Age of Prozac. New York: John Wiley \& Sons Inc., 1997.

24. MAJ M. Mental disorders as 'brain diseases and Jaspers' legacy. World Psychiatry 2013;12:1-3.

25. Insel T, Cuthbert B, Garvey $M$ et al. Research domain criteria (RDoC): toward a new classification framework for research on mental disorders. Am J Psychiatry 2010;167:748-751.

26. DE LEON J. One hundred years of limited impact of Jaspers's general psychiatry on US psychiatry. J Nerv Ment Dis 2014;202:79-87.

27. Hyman SE. Can neuroscience be integrated into the DSM-V? Nature Rev Neurosci 2007;8:725-732.

28. Insel TR, Scolnick EM. Cure therapeutics and strategic prevention: raising the bar for mental health research. Mol Psychiatry 2006;11:11-17.

29. Evans JS. Dual-processing accounts of reasoning, judgment, and social cognition. Annu Rev Psychol 2008;59:255-278.

30. Gaudiano BA, Miller IW. The evidence-based practice of psychotherapy: facing the challenges that lie ahead. Clin Psychol Rev 2013;33:813-824.

31. KAZDIN AE. Understanding how and why psychotherapy leads to change. Psychother Res 2009;19:418-428.

32. LiNDEN DE. Brain imaging and psychotherapy: methodological considerations and practical implications. Eur Arch Psychiatry Clin Neurosci 2008;258(Suppl. 5):71-75.

33. Peres J, Nasello AG. Psychotherapy and neuroscience: towards closer integration. Int J Psychol 2008;43:943-957.
34. Robins E, Guze SB. Establishment of diagnostic validity in psychiatric illness: its application to schizophrenia. Am J Psychiatry 1970;126:983-987.

35. KLerman GL. The evolution of a scientific nosology. In Shershow JC, editor. Schizophrenia: Science and Practice. Cambridge, MA: Harvard University Press, 1978: 99-121.

36. Dean CE. The death of specificity in psychiatry: cheers or tears? Perspect Biol Med 2012;55:443-460.

37. Decker HS. How Kraepelinian was Kraepelin? How Kraepelinian are the neo-Kraepelinians? -from Emil Kraepelin to DSM-III. Hist Psychiatry 2007;18:337-360.

38. DE LEON J. DSM-5 and research domain criteria: one hundred years after Jaspers's general psychopathology. Am J Psychiatry 2014;17:492-494.

39. McHugh P, Slavney PR. The Perspectives of Psychiatry, 2nd edn. Baltimore, MD: The Johns Hopkins University Press, 1998.

40. McHugh PR. Striving for coherence: psychiatry's efforts over classification. JAMA 2005;293:2526-2528.

41. Marková IS, Berrios GE. Epistemology of mental symptoms. Psychopathology 2009;42:343-349.

42. Berrios GE, Markova IS. Symptoms - historical perspective and effect on diagnosis. In Blumenfield $\mathbf{M}$, Strain JJ, editors. Psychosomatic medicine. Philadelphia, PA: Lippincott Williams \& Wilkins, 2006. p. 27-38.

43. WigGins OP, Schwartz MA. Karl Jaspers' multiperspectivalism. Psychopathology 2013;46:289-294.

44. Gнаемі SN. Pluralism in psychiatry: Karl Jaspers on science. Phil Psychiatry Psychol 2007;14:37-66.

45. Stanghellini G. The grammar of the psychiatric interview. A plea for the second-person mode of understanding. Psychopathology 2007;40:69-74.

46. Nordgaard J, Sass LA, Parnas J. The psychiatric interview: validity, structure, and subjectivity. Eur Arch Psychiatry Clin Neurosci 2013;263:353-364.

47. Nordgaard J, Revsbech R, Saebye D, Parnas J. Assessing the diagnostic validity of a structured psychiatric interview in a first-admission hospital sample. World Psychiatry 2012;11:181-185.

48. DE LEON J. Paradoxes of US psychopharmacology practice in 2013: undertreatment of severe mental illness and overtreatment of minor psychiatric problems. J Clin Psychopharmacol 2014;34:545-548.

49. DE LEON J. Get ready to become ignorant with age: letter to James. The Other Side (A University of Kentucky Literary Magazine) 2014;3:14-15.

50. Mundt C. Jaspers concept of 'limit situation': extensions and therapeutic applications. In Fuchs T, Breyer T, Mundt C, editors. Karl Jaspers philosophy and psychopathology. New York, NY: Springer, 2014:169-178.

51. DE LEON J. A post-DSM-III wake-up call to European psychiatry. Acta Psychiatrica Scandinavica 2014;129:76-77.

52. DE LeON J. Is it time to wake up Sleeping Beauty? European psychiatry has been sleeping since 1980. Rev Psiquiatr Salud 2014; pii:S1888-9891(14)00002-0. doi:10.1016/j. rpsm.2013.12.004. [Epub ahead of print].

53. Hoenig J. Kurt Schneider and Anglophone psychiatry. Compr Psychiatry 1982;23:391-400.

54. Huber G. Kurt Schneider: the man and his scientific work. Zentralblatt Neurol Psychiatr 1987;246:177-191.

55. JANZARIK W. Jaspers, Kurt Schneider and the Heidelberg school of psychiatry. Hist Psychiatry 1998;9:241-252.

56. SChNeIDER K. Clinical Psychopathology. London, UK: Grune \& Stratten, 1959. 


\section{Psychiatry neurology or abnormal psychology}

57. Kumazaki T. The theoretical root of Karl Jaspers' general psychopathology. Part 2: the influence of Max Weber. Hist Psychiatry 2013;24:259-273.

58. INSEL T. Director's Blog: transforming diagnosis. April 29, 2013. Available at http://www.nimh.nih.gov/about/director/2013/ transforming-diagnosis.shtml. Accessed September 10, 2014.

59. GuY W, BAN TA. The AMDP-System. Heidelberg, Germany: Springer, 1982.

60. Carroll BT, Kirkhart R, Ahuja N et al. Katatonia: a new conceptual understanding of catatonia and a new rating scale. Psychiatry (Edgmont) 2008;5:42-50.

61. AndReasen NC. Scale for the Assessment of Negative Symptoms (SANS). Iowa City: University of Iowa, 1983.

62. AndREASEN NC Scale for the Assessment of Positive Symptoms (SAPS). Iowa City: University of Iowa, 1983.

63. Pelayo-Terán JM, Diaz FJ, Pérez-Iglesias R et al. Trajectories of symptom dimensions in short-term response to antipsychotic treatment in patients with a first episode of non-affective psychosis. Psychol Med 2014;44:37-50.

64. Весн P. Fifty years with the Hamilton scales for anxiety and depression. A tribute to Max Hamilton. Psychother Psychosom 2009;78:202-211.

65. Young RC, Biggs JT, Ziegler VE et al. A rating scale for mania: reliability, validity and sensitivity. Br J Psychiatry 1978;133:429-435.

66. Dean CE. The death of specificity in psychiatry. Cheers or tears? Persp Biol Med 2012;55:443-460.

67. DE LEON J. The future (or lack of future) of personalized prescription in psychiatry. Pharmacol Res 2009;59:81-89.

68. Gallagher RM, KirKham JJ, Mason JR et al. Development and inter-rater reliability of the Liverpool adverse drug reaction causality assessment tool. PLoS One 2011;6:e28096.

69. GuY W. ECDEU Assessment Manual for Psychopharmacology. Washington, DC: U.S. Department of Health, Education, and Welfare, 1976.

70. Simpson GM, Angus JWS. A rating scale for extrapyramidal side effects. Acta Psychiatrica Scandinavica 1970;212(Suppl.):11-19.

71. De Leon J, Chambers A, Hyatt M et al. A Practitioner's Guide for Prescribing Antiepileptics and Mood Stabilizers for Adults with Intellectual Disabilities. New York, NY: Springer Verlag, 2012.
72. Bech P. Clinical Psychometrics. Chichester, West Sussex: Wiley-Blackwell, 2012.

73. Томва E, Весн P. Clinimetrics and clinical psychometrics: macro- and micro-analysis. Psychother Psychosom 2012;81:333-343.

74. Hoche A, Dening RG, Dening TR et al. The significance of symptom complexes in psychiatry. Hist Psychiatry 1991;2:329-343.

75. Berrios G, Dening T. Alfred Hoche and DSM-III-R. Biol Psychiatry 1991;29:93-95.

76. DE LEON J. Focusing on drug versus disease mechanisms and on clinical subgrouping to advance personalized medicine in psychiatry. Acta Neuropsychiatrica (in press).

77. Nelson PT, Smith CD, ABNer EL et al. Hippocampal sclerosis of aging, a prevalent and high-morbidity brain disease. Acta Neuropathol 2013;126:161-177.

78. Fava GA, Sonino N, Wise TN. Principles of psychosomatic assessment. Adv Psychosom Med 2012;32:1-18.

79. VAN Os J. Solutions for patients depend on whether we can bridge the divide between social and natural science research approaches in the area of mental health. Rev Psiquiatr Salud Ment 2012;5:135-138.

80. Ellenberger HF. The Discovery of the Unconscious: The History and Evolution of Dynamic Psychiatry. New York, NY: Basic Books, 1981.

81. SADLER JZ. Psychiatric molecular genetics and the ethics of social promises. J Bioeth Inq 2011;8:27-34.

82. Muglia P. From genes to therapeutic targets for psychiatric disorders - what to expect? Curr Opin Pharmacol 2011;11:563-571.

83. Insel TR, LANDis SC, Collins FS. Research priorities. The NIH BRAIN initiative. Science 2013;340:687-688.

84. Borgwardt S, Radua J, Mechelli A et al. Why are psychiatric imaging methods clinically unreliable? Conclusions and practical guidelines for authors, editors and reviewers. Behav Brain Funct 2012;8:46.

85. Poo MM. Whereto the mega brain projects? Natl Science Rev 2014;1:12-14. 